\title{
Infection, vaccination, and childhood arterial ischemic stroke
}

\section{Results of the VIPS study}

(6) PEt

Heather J. Fullerton, MD, MAS

Nancy K. Hills, PhD

Mitchell S.V. Elkind, MD, MS

Michael M. Dowling, $\mathrm{MD}, \mathrm{PhD}$

Max Wintermark, MD

Carol A. Glaser, DVM, MD

Marilyn Tan, MD

Michael J. Rivkin, MD

Luigi Titomanlio, MD, $\mathrm{PhD}$

A. James Barkovich, MD Gabrielle A. deVeber, $\mathrm{MD}, \mathrm{MSc}$

On behalf of the VIPS Investigators

Correspondence to Dr. Fullerton:

Heather.Fullerton@ucsf.edu

Editorial, page 1438

Supplemental data at Neurology.org

\section{ABSTRACT}

Objectives: Minor infection can trigger adult arterial ischemic stroke (AIS) and is common in childhood. We tested the hypotheses that infection transiently increases risk of AIS in children, regardless of stroke subtype, while vaccination against infection is protective.

Methods: The Vascular Effects of Infection in Pediatric Stroke study is an international casecontrol study that prospectively enrolled 355 centrally confirmed cases of AIS (29 days-18 years old) and 354 stroke-free controls. To determine prior exposure to infections and vaccines, we conducted parental interviews and chart review.

Results: Median (interquartile range) age was 7.6 years for cases and 9.3 for controls ( $p=0.44$ ). Infection in the week prior to stroke, or interview date for controls, was reported in $18 \%$ of cases, vs $3 \%$ of controls, conferring a 6.3-fold increased risk of AIS ( $p<0.0001$ ); upper respiratory infections were most common. Prevalence of preceding infection was similar across stroke subtypes: arteriopathic, cardioembolic, and idiopathic. Use of vasoactive cold medications was similarly low in both groups. Children with some/few/no routine vaccinations were at higher stroke risk than those receiving all or most (odds ratio [OR] 7.3, $p=0.0002$ ). In an age-adjusted multivariate logistic regression model, independent risk factors for AIS included infection in the prior week (OR 6.3, $p<0.0001$ ), undervaccination (OR 8.2, $p=0.0004$ ), black race (compared to white; OR 1.9, $p=0.009$ ), and rural residence (compared to urban; OR 3.0, $p=0.0003$ ).

Conclusions: Infection may act as a trigger for childhood AIS, while routine vaccinations appear protective. Hence, efforts to reduce the spread of common infections might help prevent stroke in children. Neurology ${ }^{\circledR}$ 2015;85:1459-1466

\section{GLOSSARY}

AIS = arterial ischemic stroke; $\mathbf{C l}=$ confidence interval; IQR = interquartile range; $\mathbf{O R}=$ odds ratio; PFO = patent foramen ovale; SES = socioeconomic status; VIPS = Vascular Effects of Infection in Pediatric Stroke.

Ischemic stroke affects at least 2.4 per 100,000 US children every year. ${ }^{1,2}$ Historical impressions that children recover well from stroke have been contradicted by outcome studies that document a high rate of lifelong morbidity. ${ }^{3-5}$ A better understanding of the causes of childhood stroke is needed to develop strategies for prevention.

Major infections - bacterial meningitis, sepsis, endocarditis - have long been associated with arterial ischemic stroke (AIS) in children. Minor infections occur more frequently, and have been linked to AIS risk in adults. ${ }^{6-14}$ In a retrospective case-control study set in Northern California, we found that a medical encounter for minor infection transiently increased AIS risk 15-fold ( $p<0.0001)$ over a 3-day period, and that this risk factor was present in $10 \%$ of childhood AIS cases. ${ }^{15}$ This suggests a potential opportunity for primary stroke prevention

\footnotetext{
From the Departments of Neurology (H.J.F., N.K.H., A.J.B.), Pediatrics (H.J.F., C.A.G., A.J.B.), Biostatistics and Epidemiology (N.K.H.), and Radiology (A.J.B.), University of California San Francisco; the Departments of Neurology and Epidemiology (M.S.V.E.), Columbia University College of Physicians and Surgeons and Mailman School of Public Health, New York, NY; the Departments of Pediatrics and Neurology and Neurotherapeutics (M.M.D.), UT Southwestern Medical Center, Dallas, TX; the Department of Radiology (M.W.), Stanford University, Palo Alto, CA; the Division of Communicable Disease Control (C.A.G.), Center for Infectious Diseases, California Department of Public Health, Richmond; the Departments of Pediatrics and Neurosciences (M.T.), University of the Philippines-Philippine General Hospital, Manila, Philippines; the Departments of Neurology, Psychiatry, and Radiology (M.J.R.), Boston Children's Hospital, MA; the Pediatric Emergency Department (L.T.), Robert Debré Hospital, Paris Diderot University, Paris, France; and the Department of Neurology (G.A.d.), Hospital for Sick Children, Toronto, Canada.

Coinvestigators are listed on the Neurology ${ }^{\circledR}$ Web site at Neurology.org.

Go to Neurology.org for full disclosures. Funding information and disclosures deemed relevant by the authors, if any, are provided at the end of the article.
} 
Table 1 Characteristics of patients with childhood arterial ischemic stroke and age-matched controls, based on parental interview

\begin{tabular}{|c|c|c|c|}
\hline Characteristics & $\begin{array}{l}\text { Cases } \\
(\mathrm{n}=355), \mathrm{n}(\%)\end{array}$ & $\begin{array}{l}\text { Controls } \\
(\mathrm{n}=354), \mathrm{n}(\%)\end{array}$ & $p$ Value \\
\hline \multicolumn{4}{|l|}{ Demographics } \\
\hline Age, y, median (IQR) & $7.6(2.8-14.3)$ & $9.3(4.4-13.3)$ & 0.44 \\
\hline Male & $199(56.1)$ & $195(55.1)$ & 0.34 \\
\hline Race & & & 0.24 \\
\hline White & $230(64.8)$ & $223(63.0)$ & \\
\hline Black & 39 (11.0) & $26(7.3)$ & \\
\hline East Asian & 9 (2.5) & $4(1.1)$ & \\
\hline Indian/South Asian & $26(7.3)$ & $23(6.5)$ & \\
\hline Middle Eastern & $3(0.8)$ & $4(1.1)$ & \\
\hline First Nations/Aboriginal & $4(1.1)$ & $4(1.1)$ & \\
\hline Pacific Islander & $1(0.3)$ & $2(0.6)$ & \\
\hline Mixed or other & 38 (10.7) & $62(17.5)$ & \\
\hline Unknown & $5(1.4)$ & $6(1.7)$ & \\
\hline Ethnicity & & & 0.17 \\
\hline Non-Hispanic & $289(81.4)$ & $276(78.0)$ & \\
\hline Hispanic & 47 (13.2) & 45 (12.7) & \\
\hline Mixed or other & $19(5.4)$ & 33 (9.3) & \\
\hline Country & & & $0.001^{\mathrm{a}}$ \\
\hline United States & $223(62.8)$ & $188(53.1)$ & \\
\hline Canada & 60 (16.9) & 121 (34.2) & \\
\hline Australia & $16(4.5)$ & $3(0.8)$ & \\
\hline Philippines & $16(4.5)$ & $12(3.4)$ & \\
\hline Chile & 14 (3.9) & $13(3.7)$ & \\
\hline United Kingdom & $11(3.1)$ & $6(1.7)$ & \\
\hline France & $6(1.7)$ & $3(0.8)$ & \\
\hline Serbia & $5(1.4)$ & $4(1.1)$ & \\
\hline China & $4(1.1)$ & $4(1.1)$ & \\
\hline \multicolumn{4}{|l|}{ Socioeconomic status } \\
\hline Residence & & & $<0.0001^{a}$ \\
\hline Urban & 118 (33.2) & $184(52.0)$ & \\
\hline Suburban & $153(43.1)$ & $126(35.6)$ & \\
\hline Rural & $82(23.1)$ & $44(12.4)$ & \\
\hline Household income (in US dollars) & & & $0.001^{\mathrm{a}}$ \\
\hline$<\$ 10,000$ & 55 (15.5) & $30(8.5)$ & \\
\hline$\$ 10,000-30,000$ & 68 (19.2) & 66 (18.6) & \\
\hline$\$ 31,000-50,000$ & 47 (13.2) & $53(15.0)$ & \\
\hline$\$ 50,000-100,000$ & $90(25.4)$ & $83(23.4)$ & \\
\hline$>100,000$ & 64 (18.0) & $105(29.7)$ & \\
\hline Missing & $31(8.7)$ & $17(4.8)$ & \\
\hline Maternal education, highest level & & & $<0.0001^{\mathrm{a}}$ \\
\hline Less than high school & 43 (12.1) & $16(4.5)$ & \\
\hline High school graduate & $83(23.4)$ & $58(16.4)$ & \\
\hline Some college education & 109 (30.7) & $110(31.1)$ & \\
\hline
\end{tabular}

Continued through improved hygiene and vaccination, and potential avenues for secondary stroke prevention by expanding our understanding of stroke pathogenesis in children. The study was limited by its narrow geographic region, retrospective data, inability to measure infections not resulting in a medical encounter (or exposure to vasoactive cold medications), and poor characterization of stroke subtypes because imaging studies were not available for review.

We sought to further assess the association between infection and AIS, and test the hypothesis that vaccinations are protective, in a large, international case-control study of childhood AIS: the Vascular Effects of Infection in Pediatric Stroke (VIPS) study. We also sought to determine whether the association with infection varies by subtype: arteriopathic, cardioembolic, or idiopathic.

METHODS Setting and case enrollment. Between January 2010 and March 2014, VIPS prospectively enrolled cases of childhood AIS, and stroke-free controls, at 37 International Pediatric Stroke Study centers in 9 countries. Our target sample size (350 cases and 350 controls) was chosen to have $>80 \%$ power to detect an association between recent infection and childhood AIS subtypes, with $\alpha$ set at 0.05 . Ethics approvals were obtained at each site. Details of case ascertainment, confirmation, imaging review, laboratory analyses, and clinical data collection are published. ${ }^{16,17}$ Case inclusion criteria were age 29 days through 18 years at the time of AIS, brain MRI including cerebrovascular imaging, enrollment within 3 weeks of stroke ictus (a change from 2 weeks in the published methods), and consent/assent to study participation including blood collection. Local research staff abstracted data from medical records, interviewed parents/guardians, and mailed neuroimaging studies on $\mathrm{CD}$ to the imaging core at the University of California San Francisco.

Case confirmation and classification of stroke subtype. Cases were confirmed centrally by 2 investigators, with adjudication by a third, using pre-established clinical and imaging criteria for AIS. ${ }^{16}$ All cases were subjected to a rigorous process for classifying the presence and type of an arteriopathy. ${ }^{17}$ Cases with no arteriopathy were further classified as cardioembolic if there was a history of congenital or acquired heart disease, excluding isolated patent foramen ovale (PFO); presumed embolic with prothrombotic condition if the child had an acquired (e.g., sepsis) or genetic prothrombotic condition; other etiology if there was another established stroke cause or risk factor; and idiopathic if no stroke risk factors were identified. Children with only PFO or migraine were considered idiopathic. Cardioembolic strokes were further classified as procedure-related, if coincident with a cardiac procedure, or spontaneous.

Control enrollment. VIPS enrolled stroke-free controls aged 29 days through 18 years. Controls were selected to minimize bias either towards or against having a recent infection. There 


\begin{tabular}{|c|c|c|c|}
\hline Continued & & & \\
\hline Characteristics & $\begin{array}{l}\text { Cases } \\
(\mathrm{n}=355), \mathrm{n}(\%)\end{array}$ & $\begin{array}{l}\text { Controls } \\
(\mathrm{n}=354), \mathrm{n}(\%)\end{array}$ & $p$ Value \\
\hline Bachelor's degree, or equivalent & 68 (19.2) & 89 (25.1) & \\
\hline Some graduate education & $8(2.3)$ & $15(4.2)$ & \\
\hline Graduate degree & $30(8.5)$ & 61 (17.2) & \\
\hline Missing & 14 (3.9) & $5(1.4)$ & \\
\hline $\begin{array}{l}\text { No. of routine visits to a doctor's office, past } \\
24 \text { months, median (IQR) }\end{array}$ & $2(2-4)$ & $2(2-4)$ & 0.06 \\
\hline \multicolumn{4}{|l|}{$\begin{array}{l}\text { Variables included in interview to detect } \\
\text { recall bias }\end{array}$} \\
\hline Umbilical hernia during infancy & $15(4.2)$ & $12(3.4)$ & 0.56 \\
\hline Abnormal head shape during infancy & $16(4.5)$ & 11 (3.1) & 0.43 \\
\hline
\end{tabular}

Abbreviation: IQR = interquartile range.

a Significant.

${ }^{\mathrm{b}}$ Range 0 to 36 visits for cases, 0 to 60 for controls.
Major infection. Major infection included diagnoses of meningitis/encephalitis and bacteremia/sepsis, as previously defined. ${ }^{16}$ These diagnoses were ascertained through chart review, and included diagnoses made after the stroke as long as the infection was thought to precede the stroke. All other infections were measured by the parental interview.

Data analysis. Interview questions that parents answered as unknown were counted as missing values. Unadjusted comparisons between cases and controls were made using $\chi^{2}$ and Fisher exact tests for categorical variables and the Wilcoxon rank sum test for continuous variables.

We used logistic regression models to identify factors associated with childhood AIS. In all models, we adjusted for age (as a categorical variable given its nonlinear relationship with AIS) to account for age-related variability in rates of exposure to infection and vaccinations, and for country income level, which would likely influence vaccination rates. For this purpose, countries were categorized as either lower and middle income countries (Philippines, Serbia, and China) or high-income countries (all others), as defined by the World Bank in 2014 (http://data.worldbank.org/ country; accessed November 25, 2014). In our final multivariable models, we also adjusted for race, because of previously reported racial differences in childhood stroke risk, ${ }^{18}$ season (because of seasonal variation in infection), and socioeconomic status (SES). Our markers of SES (urban/suburban/rural residence, household income, and highest level of maternal education) were highly correlated with one another; we alternated these indicators in multivariable models and compared results. Our primary analyses included children with major infections. To account for the fact that controls would be less likely to have been diagnosed with a major infection, we conducted sensitivity analyses excluding cases with major infection. To address potential selection bias related to our trauma visit controls (as a current infection could reduce risk of trauma), we conducted additional sensitivity analyses comparing cases to each control group separately. We used Stata v12 (Stata Corporation, College Station, TX) for all analyses. towards infection, if the reason for phlebotomy is directy indirectly related to infection, or against, if undergoing an elective procedure.) The laboratory assays will be the subject of future analyses. Sites that did not have a pediatric trauma center could not feasibly enroll trauma controls. Although controls were not pairwise matched, sites were asked to enroll roughly the same number of cases as controls. In addition, age histograms and geographic maps of cases and controls were provided to the sites throughout the enrollment period to encourage a similar demographic distribution.

Parental interview. Parents/guardians participated in a structured interview (appendix e-1 on the Neurology ${ }^{\circledR}$ Web site at Neurology.org) performed as soon as possible (maximum of 1 week after enrollment, or 3 weeks after stroke, whichever came first). The interview included questions about infections and vaccinations prior to the stroke ictus (for cases), the trauma event (for trauma visit controls), or enrollment (for routine visit controls). Because recommended vaccines vary by age and country, we asked, as a general indicator of vaccine status, whether the child had received all, most, some, few, or none of the routine vaccines expected for his or her age, and classified children as poorly vaccinated if the parent responded some/few/ none. We asked about conditions that we did not expect to be associated with AIS (umbilical hernia and abnormal head shape during infancy) as a measure of recall bias. Exposure to vasoactive medications was assessed using lists of medications and locally available brand name cold remedies known to contain them. Diphenhydramine, a common nonvasoactive ingredient in cold remedies, was included to gauge recall bias.
RESULTS VIPS sites screened 650 potential cases, and enrolled 387 (160 did not meet inclusion criteria, 64 did not consent, and 39 had an inadequate blood sample); 32 were excluded upon central review. The study included 355 confirmed cases and 354 controls (234 routine visit and 120 trauma visit). Parental interviews were performed at a median (interquartile range [IQR]) of $1(0-3)$ day after case enrollment (6 [4-11] days after stroke) and $0(0-0)$ days after control enrollment. The trauma visit controls were similar to routine visit controls except more likely to be older, male, Canadian, and residing in a rural area (table e-1). Demographics were similar between cases and controls, except for country of enrollment and SES (table 1). Although case and control age was similar when the controls were combined, the trauma visit controls were older (figure). Cases were similar to controls in frequency of doctor's appointments and parental report of umbilical hernia or abnormal head shape.

Stroke subtype, comorbidities and risk factors, presentation, and infarct characteristics have been published. ${ }^{17}$ Of the 355 cases, 127 (36\%) had a 
Figure Age and seasonal distributions of childhood arterial ischemic stroke cases and controls



B



C

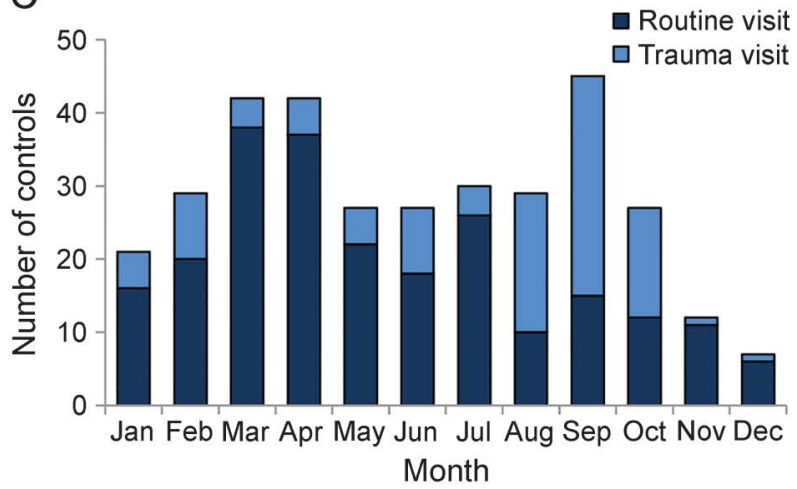

Histograms demonstrate $(A)$ age distribution of cases of childhood arterial ischemic stroke ( $n=355)$, routine visit controls ( $n=234)$, and trauma visit controls ( $n=120)$; $(B)$ seasonal distribution of arterial ischemic strokes in northern hemisphere children, stratified by those with ( $n=63$ ) vs without ( $n=262$ ) infection in the prior week; and (C) seasonal distribution of enrollment of routine visit controls $(n=234)$ and trauma visit controls $(n=120)$. (All controls were enrolled in the northern hemisphere.)

definite arteriopathy, $34(10 \%)$ a possible arteriopathy, and 194 (55\%) no arteriopathy, including 76 (21\%) cardioembolic (65 spontaneous and 11 procedure-related), 9 (3\%) presumed embolic with a prothrombotic condition, 19 (5\%) with another etiology (genetic syndrome, $\mathrm{n}=10$; meningitis/ encephalitis, head trauma, and cancer, each $n=3$ ), and 90 (25\%) idiopathic.

Exposures based on parental interview are shown in table 2. Adjusted only for age, cases were more likely than controls to have a reported infection in the prior week (odds ratio [OR] 6.3, 95\% confidence interval [CI] 3.3-12, $p<0.0001$ ), prior month (OR $2.3,95 \%$ CI $1.6-3.2, p<0.0001)$, and prior 6 months (OR 1.3, 95\% CI 0.97-1.8, $p=0.08$ ). After also adjusting for infection in the prior week, neither infection in the prior month (OR 1.4, 95\% CI 0.92$2.0, p=0.12$ ) nor prior 6 months (OR 1.1, 95\% CI $0.80-1.5, p=0.53$ ) remained significant. Of the 64 cases reporting recent infections (prior week), 32 (50\%) had upper respiratory infections and 33 $(52 \%)$ had a fever. Few cases or controls reported exposure to cold medications. In comparing routine visit to trauma visit controls, there were no differences in infection in the prior week (table e-1), or in associated signs/symptoms, or exposure to cold medications (data not shown).

Strokes occurred in all months of the year, but those preceded by infection showed seasonal variation (figure). Stroke cases with infection in the prior week had a median age of 4.0 years (IQR 1.5-8.7) compared to $9.1(3.5-15)$ for those without a preceding infection $(p<0.001)$, but there were otherwise no differences between those with or without infection in demographics or stroke presentation, location, or size (data not shown). Preceding infection was common across stroke subtypes, reported in 19 of 127 (15\%) with arteriopathic, 14 of 65 (22\%) with spontaneous cardioembolic, and 18 of 90 (20\%) with idiopathic AIS $(p=0.17)$. It was also common across subtypes of arteriopathy: 8 of 34 (24\%) with moyamoya, 3 of 25 (12\%) with transient cerebral arteriopathy, and 2 of $26(8 \%)$ with arterial dissection $(p=0.22)$.

By parental report, controls were generally better vaccinated than cases (table 3). Having had a vaccination in the prior week (of any type) was associated with a reduced risk of AIS (OR 0.23, 95\% CI $0.10-0.52, p=0.0005)$. Vaccination rates varied by country income level, but controls were better vaccinated than cases in each strata (table e-2). Vaccination rates were similar between routine visit and trauma visit controls, with $97 \%$ of both groups receiving all or most routine vaccines expected for their age (table e-1).

In the multivariable logistic regression model (table 4), recent infection (prior week) and being poorly vaccinated remained independent predictors of childhood AIS, as did lower SES (rural residence shown, but findings were similar for household income and maternal education). In a sensitivity analysis excluding 34 cases with medical record documentation of major infection ( $\mathrm{n}=13$ sepsis/ bacteremia, $\mathrm{n}=15$ meningitis/encephalitis, $\mathrm{n}=7$ both), and using the same variables in the model, the strength of the association for recent infection 


\begin{tabular}{|c|c|c|c|}
\hline \multirow[t]{2}{*}{$\begin{array}{l}\text { Exposures to infection a } \\
\text { childhood arterial ischen } \\
\text { measured by parental in }\end{array}$} & \multicolumn{3}{|c|}{$\begin{array}{l}\text { d cold medications among patients with } \\
\text { ic stroke and age-matched controls, } \\
\text { erview }\end{array}$} \\
\hline & $\begin{array}{l}\text { Cases } \\
(\mathrm{n}=355), \mathrm{n}(\%)\end{array}$ & $\begin{array}{l}\text { Controls } \\
(\mathrm{n}=354), \mathrm{n}(\%)\end{array}$ & p Value \\
\hline \multicolumn{4}{|l|}{ Any infection in the: } \\
\hline Prior week & 64 (18.0) & $12(3.4)$ & $<0.0001^{\mathrm{a}}$ \\
\hline Prior month & $137(38.6)$ & 77 (21.8) & $<0.0001^{\mathrm{a}}$ \\
\hline Prior 6 months & $191(53.8)$ & $164(46.3)$ & 0.08 \\
\hline \multicolumn{4}{|l|}{ Recent infection (prior week) } \\
\hline \multicolumn{4}{|l|}{ Type of illness } \\
\hline Cold/upper respiratory infection & $32(9.0)$ & $9(2.5)$ & $0.0002^{a}$ \\
\hline Stomach flu/gastroenteritis & $9(2.5)$ & $0(0)$ & $0.004^{\mathrm{a}}$ \\
\hline Ear infection/otitis media & $7(2.0)$ & $1(0.3)$ & 0.07 \\
\hline Pneumonia & $5(1.4)$ & $0(0)$ & 0.06 \\
\hline Flu/influenza & $3(0.8)$ & $0(0)$ & 0.25 \\
\hline Bronchitis & $2(0.6)$ & $0(0)$ & 0.5 \\
\hline Sinusitis & $2(0.6)$ & $0(0)$ & 0.5 \\
\hline Meningitis & $2(0.6)$ & $0(0)$ & 0.5 \\
\hline Strep pharyngitis & $1(0.3)$ & $1(0.3)$ & 1 \\
\hline Mastoiditis & $0(0)$ & $0(0)$ & NA \\
\hline Urinary tract infection & $0(0)$ & $0(0)$ & NA \\
\hline Chicken pox & $0(0)$ & $0(0)$ & NA \\
\hline Roseola & $0(0)$ & $0(0)$ & NA \\
\hline Taken to a doctor for the illness & 45 (12.7) & $3(0.8)$ & $<0.0001^{\mathrm{a}}$ \\
\hline Treated with antibiotics for the illness & $31(8.7)$ & 2 (0.6) & $<0.0001^{a}$ \\
\hline Missed school for the illness & $23(6.5)$ & $2(0.6)$ & $<0.0001^{\mathrm{a}}$ \\
\hline \multicolumn{4}{|l|}{ Associated signs/symptoms } \\
\hline Cough & $36(10.1)$ & $8(2.3)$ & $<0.0001^{a}$ \\
\hline $\begin{array}{l}\text { Fever (temperature }>101^{\circ} \mathrm{F} \text { or } \\
38.5^{\circ} \mathrm{C} \text { ) }\end{array}$ & $33(9.3)$ & $4(1.1)$ & $<0.0001^{a}$ \\
\hline Runny nose & $30(8.5)$ & $6(1.7)$ & $<0.0001^{\mathrm{a}}$ \\
\hline Vomiting & $17(4.8)$ & $0(0)$ & $<0.0001^{\mathrm{a}}$ \\
\hline Sore throat & $10(2.8)$ & $5(1.4)$ & 0.19 \\
\hline Diarrhea & $8(2.3)$ & $0(0)$ & $0.008^{\mathrm{a}}$ \\
\hline Ear pain & $4(1.1)$ & $1(0.3)$ & 0.37 \\
\hline Rash & $3(0.8)$ & $0(0)$ & 0.25 \\
\hline Ulcers in mouth & $1(0.3)$ & $0(0)$ & 1 \\
\hline Urinary frequency & $1(0.3)$ & $0(0)$ & 1 \\
\hline Pain with urination & $0(0)$ & $0(0)$ & NA \\
\hline Ulcers on hands/feet & $0(0)$ & $0(0)$ & NA \\
\hline \multicolumn{4}{|l|}{ Cumulative infections (prior 6 months) } \\
\hline $\begin{array}{l}\text { Total infectious illnesses, median } \\
\text { (range) }\end{array}$ & $1(0-17)$ & $1(0-6)$ & 0.18 \\
\hline Total days of illness, median (range) & $4(0-180)$ & $3(0-100)$ & $0.0009^{a}$ \\
\hline $\begin{array}{l}\text { No. of physician visits for illness, } \\
\text { median (range) }\end{array}$ & $0(0-14)$ & $0(0-6)$ & $<0.0001^{a}$ \\
\hline $\begin{array}{l}\text { Total school/daycare days missed } \\
\text { for illness, median (range) }\end{array}$ & $0(0-180)$ & $0(0-40)$ & 0.65 \\
\hline
\end{tabular}

Continued was similar (OR 6.5, $p<0.0001$ ), while the OR for being poorly vaccinated lowered from 8.2 to 5.9, but remained significant $(p=0.005)$. In a second sensitivity analysis, we created models comparing cases to only routine visit controls, and only trauma visit controls; CIs widened, but the findings were similar (table e-3).

DISCUSSION In this prospective, international casecontrol study of childhood stroke, infection transiently increased risk of childhood AIS, regardless of stroke subtype, while routine vaccinations appeared protective. These associations persisted even after adjusting for age, sex, season, and SES. A preceding infection alone does not fully explain why AIS occurred in a child; it increases risk only 6-fold while the baseline population risk is very low. Rather, infection likely acts as a stroke trigger in a child who is otherwise predisposed, and explains why the stroke happened at a particular point in that child's life.

Major infections have long been considered etiologies of AIS in both children and adults, while a more recent body of literature suggests that minor infections can also act as a trigger for stroke in adults. ${ }^{6-14}$ Although utilizing different methods to ascertain infection, a handful of studies have suggested that minor infection is common prior to AIS in childhood. The International Pediatric Stroke Study registry reported infection as a stroke risk factor in $24 \%$ of 676 AIS cases enrolled in 10 countries, although infection, including a time frame for exposure, was not well-defined. ${ }^{19}$ A single-center UK study reported "clinical symptoms of infection" in 34\% of 212 AIS cases. ${ }^{20}$ In the only prior association study, set in the population of children receiving care from Kaiser Permanente Northern California, 33\% of 126 cases (vs $13 \%$ of controls) had a medical encounter for infection in the prior 4 weeks, ${ }^{21}$ and $14 \%$ of cases (1.7\% of controls) in the prior 7 days. ${ }^{15}$ The study reported an adjusted OR of 15 (95\% CI 3.3-68) for minor infection $\leq 3$ days prior to stroke, and OR 4.0 (0.9-17.9) for infection 4-7 days prior. ${ }^{15}$ This Kaiser study was geographically narrow, based purely on retrospective chart review, and unable to review imaging to either confirm or classify the AIS. VIPS improves upon the Kaiser study with its large sample size, broad geographic representation, prospective enrollment, and central imaging review for case confirmation and stroke classification. Despite these differences, the findings were similar. In VIPS, 39\% of cases had parental report of infection in the prior 4 weeks, and $18 \%$ in the prior 1 week. We observed a similar association between infection and childhood AIS (adjusted OR 6.5, 95\% CI 3.3-13, for infection in the prior week). 
Table 2 Continued

\section{Characteristics}

Cases

( $\mathrm{n}=355), \mathrm{n}(\%)$

Controls

(n = 354), n (\%) p Value

Exposure to cold medications

Cold medication taken in prior 24 hours

Vasoactive ingredients

Dextromethorphan

Pseudoephedrine

Phenylpropanolamine

Ephedra

Not vasoactive

Diphenhydramine

Other cough syrup or cold preparation

Cold medication taken in prior week

Vasoactive ingredients

$1(0.3)$

0 (0)

1 (0.3)

$2(0.6)$

0.62

1 (0.3)

0 (0)

$1(0.3)$

0 (0)

4 (1.1)

0 (0)

$1(0.3)$

0.12

4 (1.1)

0.37
Dextromethorphan

Pseudoephedrine

Phenylpropanolamine

Ephedra

Not vasoactive

Diphenhydramine

Other cough syrup or cold preparation

$\begin{array}{lll}5(1.4) & 1(0.3) & 0.22 \\ 2(0.6) & 2(0.6) & 1 \\ 1(0.3) & 0(0) & 1 \\ 0(0.0) & 0(0) & \mathrm{NA} \\ 6(1.7) & 0(0) & 0.03^{\mathrm{a}} \\ 9(2.5) & 2(0.6) & 0.06\end{array}$

Abbreviation: NA = not applicable.

a Significant. routine visits to a doctor's office, suggesting equal access, and the protective effect of vaccination was independent of SES in our multivariable models. Because exposures to the different individual vaccines were highly correlated, we could not determine whether any one vaccine was particularly (and independently) protective against AIS. Rather, we speculate that simply being better vaccinated affords some protection against AIS by decreasing a child's exposure to infection, and thereby decreasing periods of transient systemic inflammation.

A number of observational studies have reported no increased stroke risk after routine vaccination in adults, and some have even suggested a protective effect. $^{8,26-29}$ The only prior pediatric study to assess vaccination and stroke risk was a retrospective cohort study that examined the electronic records from 8 medical care organizations, and found no increased risk of AIS after varicella vaccination. ${ }^{30}$ However, this study assessed no other pediatric vaccines, and stroke diagnoses were based purely on billing codes, which have $<40 \%$ sensitivity for pediatric AIS. ${ }^{1}$ Our study, on the other hand, assessed a broad array of pediatric vaccinations, and used rigorous methods for confirming the stroke diagnosis. Our findings provide reassurance that vaccinations do not increase stroke risk, and may even reduce risk.

The major limitation of this analysis is the potential for selection bias, as the controls were biased against current infections severe enough to require hospital admission or, in the case of the trauma visit controls, to decrease activity and thereby reduce risk of trauma. However, the association with infection remained significant in a sensitivity analysis removing cases of AIS with major infection, and another analysis comparing cases only to the routine visit controls. Other limitations are the subjective measure of infection and ascertainment of vaccination exposure through parental report, which could have led to recall bias. However, there was no difference between cases and controls in parental report of the variables included as a measure of recall bias, the total number of infections over the prior 6 months, or exposure to cold medications. Furthermore, our prior study in the Kaiser population, although retrospective, had a measure of infection (documented medical encounter) resistant to either selection or recall bias, and similarly demonstrated an association between acute infection and childhood AIS. ${ }^{15}$ Other limitations are our inability to measure subclinical infections and that our cases and controls were not matched geographically.

Infection likely acts as a trigger for AIS in children who are otherwise predisposed to stroke, while routine childhood vaccinations may be protective. Infection control through methods like handwashing and vaccinations may be a strategy for primary stroke 

Table $3 \quad \begin{aligned} & \text { Exposures to vaccinations among patients with childhood AIS and age-matched controls, measured } \\ & \text { by parental interview }\end{aligned}$

\begin{tabular}{|c|c|c|c|c|}
\hline \multirow[b]{2}{*}{ Characteristic } & \multirow[b]{2}{*}{$\begin{array}{l}\text { Cases (N = 355), } \\
\mathrm{n} / \mathrm{N}(\%)\end{array}$} & \multirow[b]{2}{*}{$\begin{array}{l}\text { Controls ( } \mathrm{N}=354 \text { ), } \\
\mathrm{n} / \mathrm{N}(\%)\end{array}$} & \multicolumn{2}{|l|}{ Risk of AIS ${ }^{a}$} \\
\hline & & & OR (95\% Cl) & p Value \\
\hline $\begin{array}{l}\text { How many routine vaccines has your } \\
\text { child received? }\end{array}$ & & & & $0.001^{b}$ \\
\hline All expected for his or her age & 294/355 (82.8) & $320 / 354(90.4)$ & & \\
\hline Most & 21/355 (5.9) & 22/354 (6.2) & & \\
\hline Some & $16 / 355(4.5)$ & 2/354 (0.6) & & \\
\hline Few & 2/355 (0.6) & 0/354 (0.0) & & \\
\hline None & 9/355 (2.5) & 2/354 (0.6) & & \\
\hline Unknown (missing data) & $13 / 355(3.7)$ & $8 / 354(2.3)$ & & \\
\hline $\begin{array}{l}\text { Composite variable for poorly vaccinated } \\
\text { (some/few/none) }\end{array}$ & $27 / 342(7.9)$ & $4 / 346$ (1.2) & $7.3(2.5-21)$ & $0.0002^{b}$ \\
\hline \multicolumn{5}{|l|}{ Ever received a routine vaccination against ${ }^{c}$} \\
\hline MMR & 298/355 (83.9) & $327 / 354(92.4)$ & $0.40(0.24-0.68)$ & $0.0007^{b}$ \\
\hline Polio & $322 / 341(94.4)$ & 338/346 (97.7) & $0.42(0.18-0.98)$ & $0.004^{b}$ \\
\hline DPT & 332/355 (93.5) & $344 / 354$ (97.2) & $0.43(0.20-0.93)$ & $0.03^{b}$ \\
\hline Pneumococcus & 255/324 (78.7) & 285/322 (88.5) & $0.42(0.26-0.69)$ & $0.0007^{b}$ \\
\hline Varicella & 206/325 (63.4) & 258/337 (76.6) & $0.51(0.36-0.74)$ & $0.0003^{b}$ \\
\hline Meningococcus & 211/315 (67.0) & 246/323 (76.2) & $0.61(0.42-0.91)$ & $0.01^{\mathrm{b}}$ \\
\hline Hepatitis A & 200/317 (63.1) & 214/322 (66.5) & $0.88(0.62-1.25)$ & 0.48 \\
\hline Hepatitis B & 266/327 (81.3) & $263 / 340(77.4)$ & $1.3(0.96-1.01)$ & 0.17 \\
\hline Any vaccinations, prior 6 months & 109/341 (32.0) & 123/349 (35.2) & $0.82(0.59-1.15)$ & 0.25 \\
\hline
\end{tabular}

Abbreviations: AIS = arterial ischemic stroke; $\mathrm{Cl}$ = confidence interval; DPT = diphtheria/pertussis/tetanus; MMR = measles/mumps/rubella; $\mathrm{OR}=$ odds ratio.

${ }^{a}$ Adjusted for age and geographic region.

${ }^{b}$ Significant.

${ }^{\mathrm{C}}$ Excludes any who answered unknown; all measured vaccines are shown.

\begin{tabular}{|lll|}
\hline Table 4 & $\begin{array}{l}\text { Multivariate model showing independent } \\
\text { predictors of childhood arterial ischemic } \\
\text { stroke }^{\mathrm{a}}\end{array}$ \\
\hline Characteristics & OR (95\% Cl) & p Value \\
Infection in prior week & $6.3(3.2-12)$ & $<0.0001$ \\
\hline Poorly vaccinated & $8.2(2.5-26)$ & 0.0004 \\
Residence & Ref & \\
\hline Urban & $2.0(1.4-2.9)$ & 0.40 \\
\hline Suburban & $3.0(1.8-4.8)$ & 0.001 \\
\hline Rural & $0.84(0.34-2.1)$ & 0.70 \\
\hline LAMI country & & \\
\hline Race & Ref & \\
\hline White & $2.0(1.1-3.7)$ & 0.005 \\
\hline Black & $1.0(0.49-1.8)$ & 0.71 \\
\hline Asian & $0.62(0.39-0.99)$ & 0.007 \\
\hline Other/mixed/unknown & & \\
\hline
\end{tabular}

Abbreviations: $\mathrm{Cl}=$ confidence interval; $\mathrm{LAMI}=$ lower and middle income; $\mathrm{OR}=$ odds ratio; Ref $=$ reference.

${ }^{\text {a }}$ Model also adjusted for sex, season at enrollment, and age (as a categorical variable because nonlinear).

${ }^{\mathrm{b}}$ Composite variable (some/few/none routine vaccinations). prevention. A better understanding of the association between infection and AIS in children will also inform the development of strategies for prevention of recurrent stroke in this important age group.

\section{AUTHOR CONTRIBUTIONS}

The study was conceived of and designed by H.J.F. and G.A.d., with input into study design by all the authors. H.J.F., G.A.d., and M.S.V.E. provided overall coordination of the study. M.M.D., M.T., M.J.R., L.T., G.A.d., and the VIPS investigators enrolled patients and collected data. M.W., H.J.F., and A.J.B. performed the imaging reviews. N.K.H. analyzed the data. All authors contributed to the interpretation of the data. H.J.F. drafted the manuscript, and all others critically revised it.

\section{ACKNOWLEDGMENT}

The authors thank the VIPS research coordinators, patients, and their families.

\section{STUDY FUNDING}

Funded by the NIH (R01 NS062820; PIs Fullerton, deVeber). All authors receive NIH funding for this project except for Dr. Glaser.

\section{DISCLOSURE}

The authors report no disclosures relevant to the manuscript. Go to Neurology.org for full disclosures. 
16. Fullerton HJ, Elkind MS, Barkovich AJ, et al. The Vas-

\section{REFERENCES}

1. Agrawal N, Johnston SC, Wu YW, Sidney S, Fullerton HJ. Imaging data reveal a higher pediatric stroke incidence than prior US estimates. Stroke 2009;40:34153421.

2. Kleindorfer D, Khoury J, Kissela B, et al. Temporal trends in the incidence and case fatality of stroke in children and adolescents. J Child Neurol 2006;21:415-418.

3. deVeber GA, MacGregor D, Curtis R, Mayank S. Neurologic outcome in survivors of childhood arterial ischemic stroke and sinovenous thrombosis. J Child Neurol 2000; 15:316-324.

4. Lanthier S, Carmant L, David M, Larbrisseau A, de Veber G. Stroke in children: the coexistence of multiple risk factors predicts poor outcome. Neurology 2000;54:371-378.

5. De Schryver EL, Kappelle LJ, Jennekens-Schinkel A, Boudewyn Peters AC. Prognosis of ischemic stroke in childhood: a long-term follow-up study. Dev Med Child Neurol 2000;42:313-318.

6. Grau AJ, Buggle F, Heindl S, et al. Recent infection as a risk factor for cerebrovascular ischemia. Stroke 1995;26: 373-379.

7. Grau AJ, Buggle F, Becher H, et al. Recent bacterial and viral infection is a risk factor for cerebrovascular ischemia: clinical and biochemical studies. Neurology 1998;50:196-203.

8. Smeeth L, Thomas SL, Hall AJ, Hubbard R, Farrington P, Vallance P. Risk of myocardial infarction and stroke after acute infection or vaccination. N Engl J Med 2004;351: 2611-2618.

9. Bova IY, Bornstein NM, Korczyn AD. Acute infection as a risk factor for ischemic stroke. Stroke 1996;27:2204-2206.

10. Macko RF, Ameriso SF, Barndt R, Clough W, Weiner JM, Fisher M. Precipitants of brain infarction: roles of preceding infection/inflammation and recent psychological stress. Stroke 1996;27:1999-2004.

11. Syrjanen J, Valtonen VV, Livanainen M, Kaste M, Huttunen JK. Preceding infection as an important risk factor for ischaemic brain infarction in young and middle aged patients. Br Med J 1988;296:1156-1160.

12. Roquer J, Cuadrado-Godia E, Giralt-Steinthauer E, et al. Previous infection and stroke: a prospective study. Cerebrovasc Dis 2012;33:310-315.

13. Elkind MS, Carty CL, O'Meara ES, et al. Hospitalization for infection and risk of acute ischemic stroke: the Cardiovascular Health Study. Stroke 2011;42:1851-1856.

14. Elkind MS, Ramakrishnan P, Moon YP, et al. Infectious burden and risk of stroke: the northern Manhattan study. Arch Neurol 2010;67:33-38.

15. Hills NK, Sidney S, Fullerton HJ. Timing and number of minor infections as risk factors for childhood arterial ischemic stroke. Neurology 2014;83:890-897. cular effects of Infection in Pediatric Stroke (VIPS) study. J Child Neurol 2011;26:1101-1110.

17. Wintermark M, Hills NK, deVeber GA, et al. Arteriopathy diagnosis in childhood arterial ischemic stroke: results of the Vascular effects of Infection in Pediatric Stroke Study. Stroke 2014;45:3597-3605.

18. Fullerton HJ, Wu YW, Zhao S, Johnston SC. Risk of stroke in children: ethnic and gender disparities. Neurology 2003;61:189-194.

19. Mackay MT, Wiznitzer M, Benedict SL, Lee KJ, Deveber GA, Ganesan V. Arterial ischemic stroke risk factors: the International Pediatric Stroke Study. Ann Neurol 2011;69:130-140.

20. Ganesan V, Prengler M, McShane MA, Wade AM, Kirkham FJ. Investigation of risk factors in children with arterial ischemic stroke. Ann Neurol 2003;53:167-173.

21. Hills NK, Johnston SC, Sidney S, Zielinski BA, Fullerton HJ. Recent trauma and acute infection as risk factors for childhood arterial ischemic stroke. Ann Neurol 2012;72:850-858.

22. Grau AJ, Urbanek C, Palm F. Common infections and the risk of stroke. Nat Rev Neurol 2010;6:681-694.

23. Emsley HC, Hopkins SJ. Acute ischaemic stroke and infection: recent and emerging concepts. Lancet Neurol 2008;7:341-353.

24. Nagel MA, Cohrs RJ, Mahalingam R, et al. The varicella zoster virus vasculopathies: clinical, CSF, imaging, and virologic features. Neurology 2008;70:853-860.

25. Cantu C, Arauz A, Murillo-Bonilla LM, Lopez M, Barinagarrementeria F. Stroke associated with sympathomimetics contained in over-the-counter cough and cold drugs. Stroke 2003;34:1667-1672.

26. Nichol KL, Nordin J, Mullooly J, Lask R, Fillbrandt K, Iwane M. Influenza vaccination and reduction in hospitalizations for cardiac disease and stroke among the elderly. N Engl J Med 2003;348:1322-1332.

27. Wang CS, Wang ST, Lai CT, Lin LJ, Lee CT, Chou P. Reducing major cause-specific hospitalization rates and shortening hospital stays after influenza vaccination. Clin Infect Dis 2004;39:1604-1610.

28. Vila-Corcoles A, Ochoa-Gondar O, Rodriguez-Blanco T, et al. Evaluating clinical effectiveness of pneumococcal vaccination in preventing stroke: the CAPAMIS Study, 3-year follow-up. J Stroke Cerebrovasc Dis 2014;23:1577-1584.

29. Pinol-Ripoll G, de la Puerta I, Santos S, Purroy F, Mostacero E. Chronic bronchitis and acute infections as new risk factors for ischemic stroke and the lack of protection offered by the influenza vaccination. Cerebrovasc Dis 2008;26:339-347.

30. Donahue JG, Kieke BA, Yih WK, et al. Varicella vaccination and ischemic stroke in children: is there an association? Pediatrics 2009;123:e228-e234. 